\title{
Sensation seeking as a potential screening tool for suicidality in adolescence
}

\author{
Won Kyung Lee ${ }^{1}$, Dohee Lim², Hye Ah Lee ${ }^{2}$ and Hyesook Park ${ }^{2^{*}}$
}

\begin{abstract}
Background: Although suicide could be an adverse health problem related to sensation seeking, this relationship has not been rigorously evaluated. The purpose of this study was to evaluate the relationship between sensation seeking and suicidality (suicidal ideation and plan) among adolescents and to test the influence of depressive symptom on this relationship.

Methods: We surveyed 2,017 adolescents in seven middle and high schools located in urban and rural areas in 2012. A self-report questionnaire included items about demographic characteristics, sensation seeking, depressive symptom, and suicide plans. We evaluated the influence of sensation seeking on suicide plan using multiple logistic regression and causal mediation analysis.

Results: Sensation seeking was related to suicide ideation and plan. Sensation seeking was associated with a $13 \%$ greater likelihood of a suicide plan during the past 12 months as the score increased by 1 . After controlling for depressive symptom, the effect of sensation seeking was reduced, but still significantly increased the risk (adjusted odds ratio: 1.10; $95 \% \mathrm{Cl}$ : 1.04-1.16). When depressive symptom was included as a potential mediator, depressive symptom exerted an indirect effect on suicide planning that constituted $37 \%$ of the total effect of sensation seeking. There was no significant interaction between sensation seeking and either demographic variables or depressive symptom.
\end{abstract}

Conclusions: Sensation seeking can contribute to developing a suicide plan directly and indirectly via depressive symptom. Sensation seeking could be used to identify high-risk adolescents and provide proper interventions.

Keywords: Sensation seeking, Adolescence, Suicide, Depression

\section{Background}

Suicide is an important public health problem in adolescence. Globally, self-harm is related to 63,301 deaths each year and is the second leading cause of death among adolescents 15-19 years old. It has much greater influence than the general population whose suicide is the 14th greatest cause of death, accounting for 883,715 deaths in 2010 [1]. From the disease burden perspective, adolescents have been enduring heavier burden from self-harm than general population. Self-harm costs 4,373,730 disability-adjusted life years (DALYs) for ages $15-19$, the 4th greatest contribution to total burden [2]. On contrast, it accounts for $11.9 \%$ of $36,654,600$ DALYs across all ages, ranked 18th in the general population.

\footnotetext{
* Correspondence: hpark@ewha.ac.kr

${ }^{2}$ Department of Preventive Medicine, School of Medicine, Ewha Womans

University, 1071 Anyangcheon-roYangcheon-ku, Seoul 158-710, Republic of Korea Full list of author information is available at the end of the article
}

Although psychiatric disorders such as depression are often associated with suicide [3], there are insufficient screening tests for suicidality and the identification of high-risk individuals.

Sensation seeking is a personality trait characterized by "the willingness to take physical, social, legal and financial risks for the sake of seeking varied, novel, complex and intense sensation and experiences" [4]. Sensation seeking has been suggested to be related to risky driving, substance use, and risky sexual behavior [5]. Therefore, sensation seeking has been proposed to be a target for prevention programs for risk-related health problems including alcohol, drug usage, and sexually transmitted disease [6]. Suicide attempts may be an additional negative health behavior related to sensation seeking [7]. However, suicide is a mixed affective-behavioral psychopathology, and more research is needed to evaluate the relationship 
between sensation seeking and suicide and whether sensation seeking may be used as a screening test for suicidality [8]. Therefore, the purpose of this study was to evaluate the relationship between sensation seeking and suicidality (suicide ideation and plan) among adolescents. Additionally, we evaluated whether and how this relationship was influenced by depressive symptoms.

\section{Method}

\section{Study design and participants}

This study was a cross-sectional survey of students in middle and high schools located in urban, suburban, and rural areas (Seoul, Uijeongbu, and Nonsan) in Korea. We sampled a variety of seven feasible schools including girls' and boys' high schools and both standard- and advanced-curriculum schools. The survey population of seven schools was 5,439 which were all the students in seven schools and the sample population was 2,100 which came from 100 students per strata multiplied by 21 strata (3 grade X 7 schools). The classes were selected in a grade to survey at least 100 students and however the 3rd grade in high school was often impractical due to university admission schedule. The number of participants was 2,019 with overall response rate of $96.1 \%$ and the enlisted students were slightly more female $(n=1,153)$ than male participants $(n=852)$. Approximately one-third of participants $(n=633)$ attended middle school and 1,375 attended high school. The median age of the participants was 16 years old and ranged from 13 to 18 . The Ewha Womans University Institutional Review Board (IRB) approved this survey (IRB Number: 2012-07-18) and informed written consent was obtained from all participants. We explained the purpose and questionnaire of the study and got permission from the principals of the enrolled school. The school newsletter containing the survey plan was sent to the students' families and parents had opportunity to withdraw consent. This process is similar to the Youth Health Study of Korea, which is a representative sample study on middle and high school students conducted by Korea Centers for Disease Control and Prevention to survey the health issues and risk factors [9].

\section{Measures}

The questionnaire included items about demographic characteristics, sensation seeking, depressive symptom, and suicide (Additional file 1). Students answered questions regarding their experiences of suicidal ideation, planning, and attempts during the last 12 months. They also answered whether their experience of depressive symptoms during the last 12 months was enough to adversely affect their family and school life for a bout of 2 weeks or longer ("During the last 12 months, have you experienced trouble in doing normal day-to-day activities from sadness and loss of interest which persisted more than two weeks?"). Demographic characteristics included gender, grade, family income (low, lower-middle, middle, upper-middle and high) and number of siblings.

We used the Sensation-Seeking Scale developed by Slater (2003). It consists of two questions: "How often do you do dangerous things for fun?" and "How often do you do exciting things, even if they are dangerous?" rated using a 5-point scale from 1 (not at all) to 5 (a lot) [10]. This brief index of sensation seeking focuses on the risktaking elements of sensation seeking and was developed for screening and large-scale surveys (Cronbach's $\alpha=0.81$ ) [11]. This scale has very good internal validity and is correlated with substance use. We used sensation-seeking scale as a continuous variable in the logistic regression model and evaluated the odds ratio per a scale. For interpretation, the participants were divided into two group (high and low sensation seeker) in mediation analysis. High sensation seeking was defined as sensation seeking scores of 3.0 or greater, which corresponded to the 75th percentile in our study. Lower scores were considered indicative of low sensation seeking. The cutoff was chosen as the model using the 3rd quartile had lower AIC (Akaike Information Criterion) compared to those with the median, the 2nd tertile, and the 90th percentile [12-14].

\section{Data analysis}

Demographic characteristics of gender, grade, family income, and number of siblings are presented in Table 1 based on extent of suicide ideation and planning. Multiple logistic regression was used to examine the effect of sensation seeking and demographic characteristics on suicide ideation and planning. The interactions between sensation seeking and both demographics and depressive symptoms were also evaluated. We evaluated the influence of sensation seeking on suicidality (suicidal ideation and plan) and whether this influence depended on one's depressive symptoms. This was done by calculating depressive symptom as a mediator of an assumed causal relationship between sensation seeking and suicide planning. In this causal-mediation analysis, we included gender, grade, family income, and number of siblings as covariates. Analyses were conducted using $\mathrm{R}$ version 3.1.2 (R Foundation for Statistical Computing, Vienna, Austria) running the statistical package "mediation." All reported $p$-values are two-sided and considered significant if less than 0.05 .

\section{Results}

\section{Suicidality and demographic variables}

Two participants did not respond to the question regarding suicide ideation and plan during the past 12 months (response rate: 2,017 of 2,019 participants). Of these respondents, $10.3 \%$ reported suicidal ideation, $4.0 \%$ 
Table 1 Participant demographics by suicide ideation and planning

\begin{tabular}{|c|c|c|c|c|c|c|c|}
\hline & \multirow[t]{2}{*}{$N$} & \multicolumn{3}{|c|}{ Suicide planning $(N=80)$} & \multicolumn{3}{|c|}{ Suicide ideation $(N=207)$} \\
\hline & & $n$ & $\%$ & $p$-value & $n$ & $\%$ & $p$-value \\
\hline \multicolumn{8}{|l|}{ Gender } \\
\hline Male & 852 & 37 & 4.3 & 0.495 & 90 & 10.6 & 0.769 \\
\hline Female & 1,153 & 42 & 3.6 & & 116 & 10.1 & \\
\hline \multicolumn{8}{|l|}{ Grade } \\
\hline 1st middle school & 189 & 14 & 7.4 & $<0.01$ & 32 & 16.9 & $<0.01$ \\
\hline 2nd middle school & 250 & 16 & 6.4 & & 43 & 17.5 & \\
\hline 3rd middle school & 194 & 10 & 5.2 & & 22 & 11.4 & \\
\hline 1st high school & 607 & 18 & 3.0 & & 50 & 8.3 & \\
\hline 2nd high school & 555 & 14 & 2.5 & & 35 & 6.3 & \\
\hline 3rd high school & 213 & 7 & 3.3 & & 24 & 11.3 & \\
\hline \multicolumn{8}{|l|}{ Family Income } \\
\hline Low & 80 & 7 & 8.8 & $<0.01$ & 12 & 15.0 & $<0.01$ \\
\hline Lower-middle & 300 & 15 & 5.0 & & 38 & 12.7 & \\
\hline Middle & 1,064 & 28 & 2.6 & & 80 & 7.5 & \\
\hline Upper-middle & 430 & 24 & 5.6 & & 59 & 13.8 & \\
\hline High & 112 & 5 & 4.5 & & 15 & 13.4 & \\
\hline \multicolumn{8}{|l|}{ No. of Siblings } \\
\hline 1 & 242 & 15 & 6.2 & 0.093 & 29 & 12.0 & 0.165 \\
\hline 2 & 1,335 & 45 & 3.4 & & 125 & 9.4 & \\
\hline$\geq 3$ & 418 & 19 & 4.5 & & 51 & 12.2 & \\
\hline Sensation-seeking score ${ }^{a}$ & $4.0(2.0-6.0)$ & $5.0(3.0-6.0)$ & & $<0.01$ & $5.0(3.0-6.0)$ & & $<0.01$ \\
\hline \multicolumn{8}{|l|}{ Symptoms } \\
\hline Non-depressive & 1,683 & 31 & 1.8 & $<0.01$ & 101 & 6.0 & $<0.01$ \\
\hline Depressive & 327 & 48 & 14.7 & & 105 & 32.1 & \\
\hline
\end{tabular}

Note: Percentages are based on different numbers of participants depending on frequency of answering

${ }^{\mathrm{a}}$ Median and interquartile range (Q1-Q3), $P$-value for Wilcoxon rank sum test

reported a suicide plan, and $2.1 \%$ reported a suicide attempt. Suicide ideation and planning differed by grade, family income, sensation seeking, and depressive symptoms (Table 1). Specifically, middle school students reported more suicide planning than high school students. The percentage of students reporting suicide planning was lowest among students with middle- and high-income families. When it came to suicide ideation, the relationship to family income was likely to be U-shaped. Gender and number of siblings was not significantly related to suicide ideation and planning. More adolescents reported suicide planning in the high-sensation-seeking group. Total participants had the median value of 4 (interquartile range: 2-6), while those with suicidal ideation or plan had 5 (interquartile range: 3-6). Students with depressive symptoms were 26.1 and $12.9 \%$, respectively, more likely to report having suicidal idea and planned a suicide than non-depressed students.
The influence of sensation seeking and depressive symptom on suicidality

The effects of sensation seeking and depressive symptoms on suicide ideation and planning are summarized in Table 2. As sensation seeking score increased by 1 , students were $13 \%$ more likely to have engaged in suicide planning. After controlling for demographics and depressive symptom, the risk of suicidal planning increased by $10 \%$ as one sensation-seeking score rose. When it came to suicidal ideation and attempt, the adjusted odds ratios became 1.06 (95\% CI: 1.02-1.11) and 1.12 (95 \% CI: 1.04-1.20), respectively.

When the participants were divided into high and low sensation seeker, those with sensation-seeking scores greater than the 3 rd quartile had a 1.43 times $(95 \% \mathrm{CI}$ : 1.12-1.81) greater likelihood of suicide planning than individuals scoring less than the 3rd quartile sensationseeking. However, sensation seeking did not influence the relationship between depressive symptom and suicide 
Table 2 Effect of participant demographics and traits on suicide ideation and planning

\begin{tabular}{|c|c|c|c|c|c|c|c|c|}
\hline & \multicolumn{4}{|c|}{ OR for suicide planning } & \multicolumn{4}{|c|}{ OR for suicide ideation } \\
\hline & $\overline{C O R}$ & $95 \% \mathrm{Cl}$ & $\mathrm{AOR}^{\mathrm{a}}$ & $95 \% \mathrm{Cl}$ & $\overline{C O R}$ & $95 \% \mathrm{Cl}$ & $\mathrm{AOR}^{\mathrm{a}}$ & $95 \% \mathrm{Cl}$ \\
\hline \multicolumn{9}{|l|}{ Gender } \\
\hline Male & 1.09 & $0.89-1.33$ & 1.02 & $0.80-1.30$ & 1.03 & 0.89-1.19 & 0.96 & $0.81-1.14$ \\
\hline Female & Ref & & Ref & & Ref & & Ref & \\
\hline \multicolumn{9}{|l|}{ Grade } \\
\hline 1st middle school & 1.48 & $0.98-2.29$ & 2.05 & $1.24-3.49$ & 1.29 & $0.95-1.76$ & 1.64 & $1.15-2.35$ \\
\hline 2nd middle school & 1.37 & $0.92-2.09$ & 1.76 & $1.10-2.94$ & 1.30 & $0.98-1.74$ & 1.57 & $1.13-2.19$ \\
\hline 3rd middle school & 1.23 & $0.80-1.93$ & 1.68 & $1.00-2.89$ & 1.01 & $0.73-1.39$ & 1.29 & $0.90-1.86$ \\
\hline 1st high school & 0.96 & $0.66-1.43$ & 1.16 & $0.75-1.88$ & 0.84 & $0.45-1.10$ & 0.97 & $0.82-1.31$ \\
\hline 2nd high school & 0.89 & $0.61-1.34$ & 1.11 & $0.71-1.81$ & 0.73 & $0.55-0.96$ & 0.92 & $0.60-1.12$ \\
\hline 3rd high school & Ref & & Ref & & Ref & & Ref & \\
\hline \multicolumn{9}{|l|}{ Family income } \\
\hline 1 & 1.79 & $1.14-2.68$ & 1.67 & $1.01-2.64$ & 1.49 & $1.04-2.11$ & 1.40 & $0.94-2.04$ \\
\hline 2 & 1.34 & $1.00-1.78$ & 1.30 & $0.93-1.80$ & 1.35 & $1.09-1.66$ & 1.35 & $1.06-1.70$ \\
\hline 3 & Ref & & Ref & & Ref & & Ref & \\
\hline 4 & 1.42 & $1.10-1.81$ & 1.16 & $0.87-1.56$ & 1.41 & $1.17-1.70$ & 1.19 & $0.96-1.47$ \\
\hline 5 & 1.27 & $0.80-1.92$ & 0.81 & $0.46-1.33$ & 1.39 & $1.01-1.89$ & 0.96 & $0.66-1.38$ \\
\hline \multicolumn{9}{|l|}{ No. of siblings } \\
\hline 1 & 1.34 & $1.00-1.76$ & 1.18 & $0.84-1.64$ & & & 0.99 & $0.76-1.27$ \\
\hline 2 & Ref & & Ref & & Ref & & Ref & \\
\hline$\geq 3$ & 1.15 & $0.89-1.46$ & 1.11 & $0.83-1.46$ & & & 1.15 & $0.94-1.40$ \\
\hline Sensation seeking & 1.13 & $1.08-1.19$ & 1.10 & $1.04-1.16$ & 1.10 & $1.06-1.14$ & 1.06 & $1.02-1.11$ \\
\hline \multicolumn{9}{|l|}{ Symptoms } \\
\hline Non-depressive & Ref & & Ref & & Ref & & Ref & \\
\hline Depressive & 2.82 & $2.27-3.51$ & 2.85 & $2.25-3.62$ & 2.97 & $2.51-3.52$ & 3.00 & $2.51-3.60$ \\
\hline
\end{tabular}

${ }^{a}$ Adjusted for gender, grade, income, number of siblings, sensation seeking, and depressive symptom

planning. The odds ratio of depressive symptom on suicide planning only changed from 2.82 to 2.85 when demographics and sensation seeking were controlled in the model.

There were no significant interactions between demographic variables and sensation seeking or between depressive symptom and sensation seeking. Interactions between demographic variables and sensation seeking were not significant when the demographic variable was gender $(p$-value $=.656)$, grade $(p$-value $=.379)$, family income $(p$-value $=.450)$ and sibling number $(p$-value $=.531)$. When it came to the relationship between depressive symptom and sensation seeking, the significant interaction was not found $(p$-value $=.338)$.

The direct and indirect effects of sensation seeking and depressive symptom on suicidality

The direct and indirect effects of sensation seeking on suicide planning were estimated using a model assuming that depressive symptom mediated this relationship (Fig. 1). In addition to a significant direct effect of

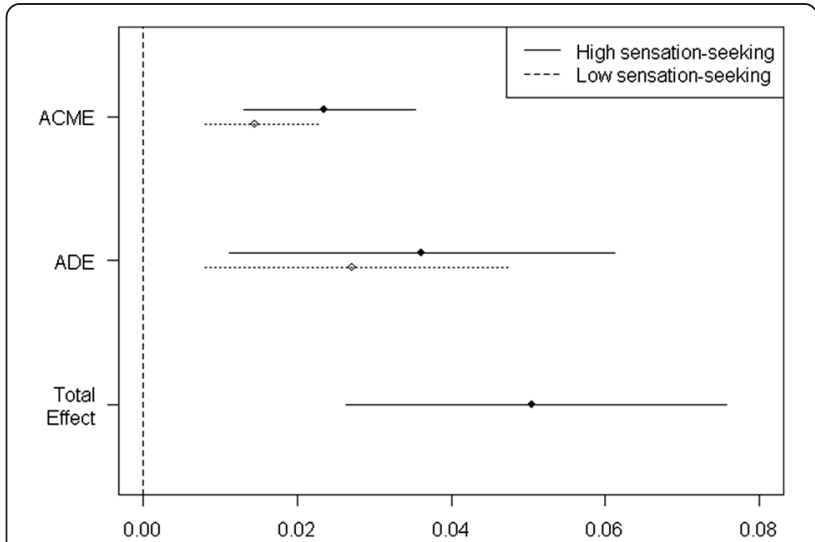

Fig. 1 The mediated and direct effects of sensation seeking on suicide planning. ACME: average causal mediation effect (separately for high sensation-seeking and low sensation-seeking group). ADE: average direct effect (separately for high sensation-seeking and low sensation-seeking group). Total effect (Average) 
sensation seeking on suicide planning, sensation seeking exerted an indirect effect via depressive symptom constituting $37 \%$ of the total effect (95\% CI: 0.21-0.69). Figure 1 shows that high sensation seekers were more prone to suicide planning both due to the direct and indirect mediated effects, though the confidence intervals between high and low sensation seekers overlapped. Among low sensation seekers, the average mediated and direct effects on suicide planning were 0.014 and 0.027 , respectively. In contrast, in the high-sensationseeking group the corresponding values were 0.023 and 0.036 , respectively.

\section{Discussion}

This study was performed to evaluate the relationships between sensation seeking, depressive symptom, and suicide planning among adolescents. We found that sensation seeking was associated with increased suicide planning using a screening test for sensation seeking in a school-based survey. There were no significant interactions between demographic variables and sensation seeking or between depressive symptom and sensation seeking. Controlling for depressive symptom did not eliminate the relationship between sensation seeking and suicide planning.

Sensation seeking may contribute to suicide planning in several ways. Previous literature has suggested that sensation seeking has a unique influence on suicide ideation after controlling for other psychopathology [15]. Some researchers have included covariates to adjust for confounders such as depression and substance use [8]. Others have included depression and interpersonal dependency [16], and evaluated neuropsychiatric interviews and personality test [7, 17]. Additionally, a case-control study showed that the only difference between a suicidal and a non-suicidal group of the psychiatric outpatients with depression was novelty-seeking [18]. Other research has found that sensation seeking could be an independent contributor to suicidal ideation and attempting suicide $[8,19]$. We found in this study that adolescents with high sensation seeking had a $43 \%$ increased risk of developing a suicide plan (AOR: 1.43; 95 \% CI: 1.12-1.81) controlling for demographic variables and depressive symptoms. This independent influence of sensation seeking can be considered consistent with the previous studies.

The independent influence of sensation seeking on suicide planning may be explained by several theories. One theory that supports the relationship between sensation seeking and suicide is the interpersonal-psychological theory of suicidal behavior [20,21]. According to this perspective, two requirements of performing a suicide are a suicidal desire and the capability to act. The suicidal desire comes from one's perceptions of burdening and social alienation. The capability to act develops through exposure and habituation to painful and fearsome experiences. Sensation seeking could also promoting one's capability to act because it is associated with a fearlessness about death and an insensitivity to pain [22]. However, our results suggest that sensation seeking is not only related to suicide attempts but also suicidal ideation and planning. Therefore, another point of view may be helpful: suicidal thoughts and desires to pursue death could fall within the spectrum of risky behaviors that sensation-seeking individuals are more willing to do [23].

Our results also suggest that sensation seeking exerts an indirect influence on suicide planning. Suicidality is a multifaceted illness which has various interacting causes and risk factors [24]. Psychological traits and states could affect suicide planning in complex and interacting ways. One factor could be a positive or negative confounder to another factor, and mediate or moderate effects on suicide planning. Relationships may be difficult to reveal and nature of its relationship remains unclear. The relationship between sensation seeking and depressive symptom requires further investigation.

Sensation seeking has been considered to be the opposite of depressive symptom. The Cardiff Depression Study showed that sensation seeking was not associated with severe life events that are typically related to depression onset, and sensation seeking was negatively associated with depression [17]. Physiological evidence has suggested that individuals with bipolar affective disorder or sensation-seeking have increased evoked potential (especially the P2 slope), while unipolar affective disorders have decreased evoked potentials [25]. Other researchers have suggested that depression can be divided into two types (sub-threshold bipolar and true unipolar) by a hypomania checklist [26]. The sub-threshold bipolar group was more likely to exhibit sensation seeking, substance use disorder, and cyclothymic temperament.

In contrast, sensation seeking could be positively associated with depressive symptom. Zuckerman, who developed the sensation seeking scale, has said of sensation seeking that "it is assumed that the high sensation seeker will become bored and nonresponsive more quickly than other persons, when stimuli and experiences become repetitive" [16]. This suggests that sensation seekers could be more susceptible to feeling tiresome and bored for any given stimuli. One previous study showed that sensation seeking had a positive relationship to anhedonia which is a primary symptom of depression [27]. Another study was performed in the smokers before and during smoking cessation with a transdermal nicotine patch. Sensation seekers were more at risk of anhedonia, affective blunting, tiredness, and lack of energy [28]. However, little is known about this relationship and it still requires more research to clarify whether depressive symptom acts as 
a confounder or mediator. If depressive symptom acts as a mediator, the present study suggests that it contributes $37 \%$ of the impact of sensation seeking on suicide planning.

This study has several limitations. First, the selection of schools may not be representative, although we covered seven middle and high schools located in urban, suburban, and rural areas. Second, data was collected using self-report questionnaires and some questions were not answered. Questions regarding family income had the lowest response rate at $98.4 \%$, while 99.9 and $99.6 \%$ of students answered questions about suicide planning and depressive symptom, respectively. Third, to reduce participant burden, we used the short screening questionnaire for sensation seeking. Therefore, more detailed information on sensation seeking and other psychiatric problems was not available. Last, the causal assumptions of the mediation analysis could not be directly tested by our cross-sectional design. Therefore, interpretations regarding causes and mediations should be tentative. Moreover, study design was a cross-sectional survey and therefore further study is needed for causality.

\section{Conclusions}

Our data suggest an influence of sensation seeking on suicide planning, independent of demographic variables and depressive symptoms. This study showed that a brief test for sensation seeking could contribute to effective screening for risk and susceptibility to suicide among adolescents. Our findings may be useful to developing school-based screening and intervention programs for high-risk sensation seekers. Education and interviews focused on this high-risk group could help to reduce rates of adolescent suicide.

\section{Additional file}

Additional file 1: The questionnaire of youth injury-related behavior survey. (DOCX $24 \mathrm{~kb})$

\section{Competing interests}

The authors declare no conflicts of interest/financial disclosures.

\section{Authors' contributions}

HP contributed to the conception and design on the study. DL was responsible for the literature review related to sensation seeking and collecting the data. HL assisted analysis and interpretation of the data. WL contributed to all the process from study design, data collection and analysis to final draft. All authors read and approved the final manuscript.

\section{Acknowledgments}

This study was supported by a grant from Ministry of Health and Welfare, Korea Centers for Disease Control and Prevention, Republic of Korea (2012E3302500) to Prof. Hyesook Park. The granting agency was not involved in the design and conduct of the study and played no role in collection, management, analysis, and interpretation of the data or in the preparation, review, or approval of the manuscript.

\section{Author details}

'Department of Social and Preventive Medicine, Inha University School of Medicine, 27 Inhang-RoJung-Gu, Incheon, Republic of Korea. ${ }^{2}$ Department of Preventive Medicine, School of Medicine, Ewha Womans University, 1071 Anyangcheon-roYangcheon-ku, Seoul 158-710, Republic of Korea.

Received: 26 May 2015 Accepted: 13 January 2016

Published online: 29 January 2016

\section{References}

1. Lozano R, Naghavi M, Foreman K, Lim S, Shibuya K, Aboyans V, et al. Global and regional mortality from 235 causes of death for 20 age groups in 1990 and 2010: a systematic analysis for the Global Burden of Disease Study 2010. Lancet. 2012;380:2095-128.

2. Murray C, Vos T, Lozano R, Naghavi M, Flaxman A, Michaud C, et al. Disability-adjusted life years (DALYs) for 291 diseases and injuries in 21 regions, 1990-2010: a systematic analysis for the Global Burden of Disease Study 2010. Lancet. 2012;380:2197-223.

3. LeFevre ML. Screening for suicide risk in adolescents, adults, and older adults in primary care: U.S. Preventive services task force recommendation statement. Ann Intern Med. 2014;160:719-26.

4. Zuckerman M. Behavioral Expression and Biosocial Bases of Sensation Seeking. New York: Cambridge University Press; 1994.

5. Roberti JM. A review of behavioral and biological correlates of sensation seeking. J Resp Pers. 2006;38(3):256-79.

6. Self DR, Findley CS. Sensation seekers as a healthcare marketing metasegment. Health Mark Q. 2010;27(1):21-47.

7. Bolognini M, Laget J, Plancherel B, Stéphan P, Corcos M, Halfon O. Drug use and suicide attempts: the role of personality factors. Subs Use Misuse. 2002; 37(3):337-56.

8. Ortin A, Lake AM, Kleinman M, Gould MS. Sensation seeking as risk factor for suicidal ideation and suicide attempts in adolescence. J Affect Disord. 2012;143(1-3):214-22.

9. Centers for Disease Control and Prevention (Korea). Youth Health Survey, 2012. [http://yhs.cdc.go.kr/] Accessed 3 January 2015.

10. Slater MD. Alienation, aggression, and sensatin seeking as predictors of adolescent use of violent film, computer, and webste content. J Commun. 2003;53:105-21.

11. Stephenson MT, Hoyle RH, Palmgreen P, Slater MD. Brief measures of sensation seeking for screening and large-scale surveys. Drug Alcohol Depend. 2003;72(3):279-86.

12. Kelly TH, Robbins G, Martin CA, Fillmore MK, Lane SD, Harrington NG, et al. Individual differences in drug abuse vulnerability: $\mathrm{d}$-Amphetamine and sensation-seeking status. Psychopharmacology. 2006;189(1):17-25.

13. Slater MD. Sensation-seeking as a moderator of the effects of peer influences, consistency with personal aspirations, and perceived harm on marijuana and cigarette Use among younger adolescents. SUBSTANCE USE \& MISUSE. 2003;38(7):865-80.

14. Arora M, Mathur N, Gupta VK, Nazar GP, Reddy KS, Sargent JD. Tobacco use in Bollywood movies, tobacco promotional activities and their association with tobacco use among Indian adolescents. Tob Control. 2012;21(5):482-7.

15. Mackenzie S, Wiegel JR, Mundt M, Brown D, Saewyc E, Heiligenstein E, et al. Depression and suicide ideation among students accessing campus health care. The American journal of orthopsychiatry. 2011;81(1):101-7.

16. Halfon O, Jeammet P, Corcos M, Bolognini M, Stéphan P, Plancherel B, et al. Personality and repeated suicide attempts in dependent adolescents and young adults. Crisis: The Journal of Crisis Intervention and Suicide Prevention. 2006;27(4):164-71.

17. Farmer A, Redman K, Harris T, Mahmood A, Sadler S, McGuffin P. Sensationseeking, life events and depression: the Cardiff depression study. Br J Psychiatry. 2001;178:549-52

18. Csorba J, Dinya E, Ferencz E, Steiner P, Bertalan G, Zsadon A. Novelty seeking: difference between suicidal and non-suicidal Hungarian adolescent outpatients suffering from depression. J Affect Disord. 2010;120(1-3): $217-20$.

19. McGirr A, Renaud J, Bureau A, Seguin M, Lesage A, Turecki G. Impulsiveaggressive behaviours and completed suicide across the life cycle: a predisposition for younger age of suicide. Psychol Med. 2008;38(3):407-17.

20. Ribeiro JD, Joiner TE. The interpersonal-psychological theory of suicidal behavior: current status and future directions. J Clin Psychol. 2009;65(12):1291-9. 
21. Joiner Jr TE, Van Orden KA, Witte TK, Selby EA, Ribeiro JD, Lewis R, et al. Main predictions of the interpersonal-psychological theory of suicidal behavior: empirical tests in two samples of young adults. J Abnorm Psychol. 2009:118(3):634-46.

22. Witte TK, Gordon KH, Smith PN, Van Orden KA. Stoicism and sensation seeking: male vulnerabilities for the acquired capability for suicide. J Res Pers. 2012;46(4):384-92.

23. Yen S, Shea MT, Sanislow CA, Skodol AE, Grilo CM, Edelen MO, et al. Personality traits as prospective predictors of suicide attempts. Acta Psychiatr Scand. 2009;120(3):222-9.

24. Zouk H, Tousignant M, Seguin M, Lesage A, Turecki G. Characterization of impulsivity in suicide completers: clinical, behavioral and psychosocial dimensions. J Affect Disord. 2006;92(2-3):195-204.

25. Brocke BBA, John R, Debener S, Heilemann H. Sensation seeking and affective disorders: characteristics in the intensity dependence of acoustic evoked potentials. Neuropsychobiology. 2000;41:24-30.

26. Fornaro $M$, Ventriglio $A$, De Pasquale $C$, Pistorio ML, De Berardis $D$, Cattaneo $\mathrm{Cl}$, et al. Sensation seeking in major depressive patients: relationship to sub-threshold bipolarity and cyclothymic temperament J Affect Disord. 2013;148(2-3):375-83.

27. Carton S, Morand P, Bungenera C, Jouvent R. Sensation-seeking and emotional disturbances in depression: relationships and evolution. J Affect Disord. 1995;34:219-25.

28. Carton S, Houezec JL, Lagrue G, Jouvent R. Relationships between sensation seeking and emotional symptomatology during smoking cessastion with nicotine patch therapy. J Affect Disord. 2000;25(5):653-62

\section{Submit your next manuscript to BioMed Central and we will help you at every step:}

- We accept pre-submission inquiries

- Our selector tool helps you to find the most relevant journal

- We provide round the clock customer support

- Convenient online submission

- Thorough peer review

- Inclusion in PubMed and all major indexing services

- Maximum visibility for your research

Submit your manuscript at www.biomedcentral.com/submit

C) Biomed Central 